\title{
Arthroscopic resection of dorsal wrist ganglion
}

\author{
Mihir R. Patel ${ }^{1 *}$, Ushma K. Butala ${ }^{2}$, Vikram D. Chauhan ${ }^{1}$, Nirlepsinh S. Thakor ${ }^{1}$
}

\begin{abstract}
${ }^{1}$ Department of Orthopaedics, K. B. Bhabha Municipal General Hospital, Bandra, Mumbai, Maharashtra, India ${ }^{2}$ Department of General Surgery, H. B. T. Medical College and Dr. R. N. Cooper Municipal General Hospital, Vile Parle, Mumbai, Maharashtra, India
\end{abstract}

Received: 05 August 2016

Accepted: 12 August 2016

*Correspondence:

Dr. Mihir R. Patel,

E-mail: mrpatel1981@gmail.com

Copyright: (c) the author(s), publisher and licensee Medip Academy. This is an open-access article distributed under the terms of the Creative Commons Attribution Non-Commercial License, which permits unrestricted non-commercial use, distribution, and reproduction in any medium, provided the original work is properly cited.

\begin{abstract}
Background: The management of dorsal wrist ganglion ranges from benign neglect to surgical excision. The purpose of this study was to study the results of arthroscopic resection of dorsal wrist ganglion.

Methods: Twenty one patients who had undergone arthroscopic dorsal wrist ganglion excision and a minimum of 3 months follow up were included. The preoperative complaint of cosmesis, pain, and duration of swelling, wrist range of motion and size of the ganglion were noted. The duration the patient took to return to a painless wrist with full range of motion was noted. Patient satisfaction with respect to cosmesis and function was noted.

Results: The mean age was 23.3 years (range: 13 to 35 years). Pre-operative wrist pain was present in 17 patients and cosmesis was a complaint in 18 patients. 5 patients had a pre-operative restricted range of motion. The mean duration and size of the ganglion was 2.6 months (range: 2 to 4 months) and $1.8 \mathrm{~cm}$ (range: 1 to $3 \mathrm{~cm}$ ) respectively. The mean duration of follow up was 14.6 months (range: 3 to 24 months). Arthroscopically, dorsal synovitis was present in 10 patients, triangular-fibro-cartilage-complex (TFCC) tear in 2 patients and chondral damage in 1 patient. The ganglion stalk was visualized in 14 patients. Complete painless wrist range of motion was obtained by 20 patients by 3 weeks post-operative. One patient had a recurrence. All the remaining patients were satisfied cosmetically and functionally with the results.

Conclusions: Arthroscopic resection is an effective treatment modality for symptomatic dorsal wrist ganglion with good functional and cosmetic results.
\end{abstract}

Keywords: Arthroscopy, Dorsal wrist ganglion, Resection

\section{INTRODUCTION}

Ganglions are the most common causes of focal masses of the hand and wrist. They arise from the synovium of joints or tendon sheaths. Dorsal wrist ganglion is the most common type of ganglion arising from the hand. ${ }^{1}$ The exact etiology is not known and the most common site of origin is the dorsal scapho-lunate ligament. A one way valve is believed to exist which allows the fluid to enter the swelling from the joint and appear most commonly between the second and fourth extensor tendon compartment. ${ }^{2}$ The management of dorsal wrist ganglion ranges from benign neglect to open surgical excision. The key to open surgical excision is identification of the ganglion stalk and excision from the base.

Open surgical excision is associated with morbidities like numbness around the scar, wrist stiffness, cosmetically unacceptable scar and a recurrence rate ranging from $10 \%$ to $40 \% .^{2,3}$ Wrist arthroscopy has been an innovation in recent times with increasing application for managing wrist pathologies. Arthroscopic resection of dorsal wrist ganglion has advantages of a minimally invasive surgery, early return to function, a more cosmetically acceptable 
result than a scar of open surgery and opportunity to diagnose and treat intra-articular pathology.

The purpose of this study was to study the results of arthroscopic resection of dorsal wrist ganglion.

\section{METHODS}

Twenty one patients underwent arthroscopic dorsal wrist ganglion resection at our institute from 2010 to 2012. Patients having clinically diagnosed symptomatic dorsal wrist ganglion were included in the study. Ultrasonography was done in all the cases to confirm that the ganglion was arising from the wrist joint. The preoperative complaints of pain and cosmesis were noted. Pre-operative wrist range of motion and size of ganglion (largest dimension) were recorded. Ganglia not arising from the wrist joint, recurrent ganglia and previously operated cases were not included in the study.

All the patients were operated by the same surgeon using the same arthroscopic technique. Regional anaesthesia with a mid-arm pneumatic tourniquet was used in all patients. With the patient lying supine on the operating table, the upper limb was positioned horizontally on a hand table. Four kilograms of weight was suspended from the index, middle and ring fingers using chinese finger traps for joint distraction (Figure1).

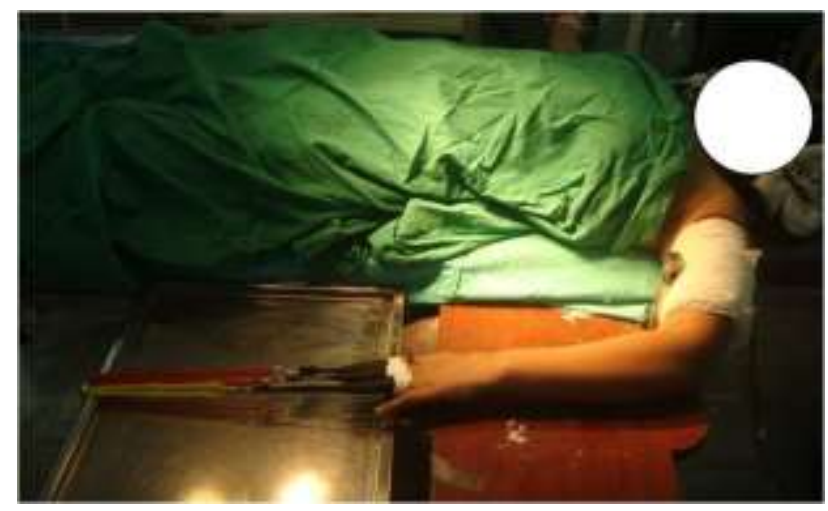

Figure 1: Patient positioning.

Skin marking of the ganglion cyst, distal radius articular margin, lister's tubercle, ulnar styloid process, tendon of the extensor pollicis longus, extensor digitorum communis and extensor carpi ulnaris was done (Figure 2).

The 3, 4 portal was made first and a diagnostic arthroscopy of the radiocarpal joint was done and presence of any pathology was noted and managed arthroscopically. The 6-R portal was then made and the scope was shifted to this portal. The dorsal capsule in the region of the scapho-lunate interosseous ligament was visualized. Attention was paid to identify the stalk of the ganglion (Figure 3). Motorized shaver blade was introduced from the 3,4 portal to debride the dorsal capsule in the region of the ganglion stalk. A needle introduced percutaneously through the centre of the ganglion and entering the joint dorsally was used to identify the site of debridement when the stalk was not visualized.

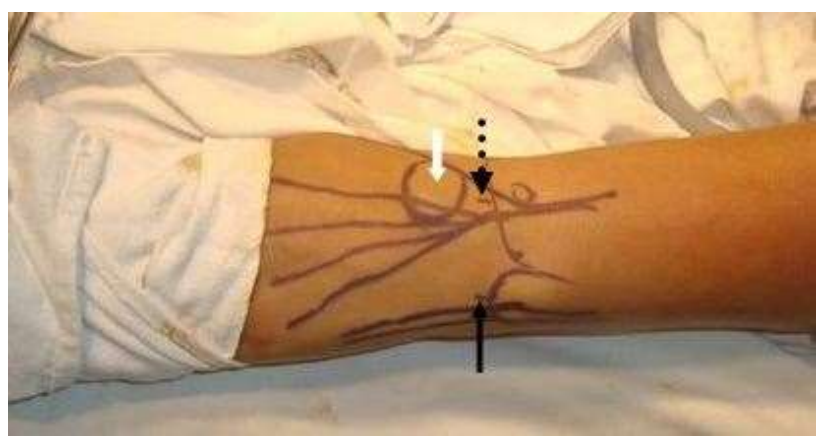

Figure 2: Skin marking and portals (white arrowganglion; dotted black arrow- 3,4 portal; solid black arrow- 6R portal).

The correct site was confirmed by pressing the ganglion and visualizing its contents emptying into the joint. The dorsal capsule was debrided till the extensor tendons could be visualized through a defect of 5 to $10 \mathrm{~mm}^{2}$.

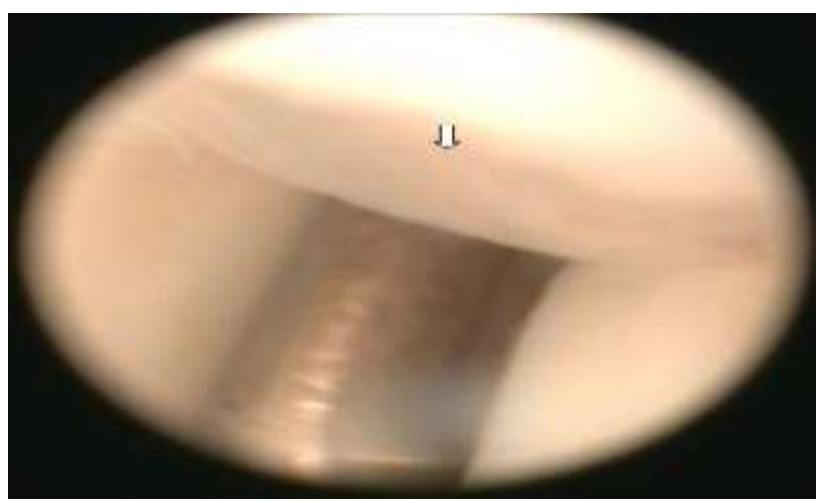

Figure 3: Arthroscopic picture of the ganglion stalk (white arrow).

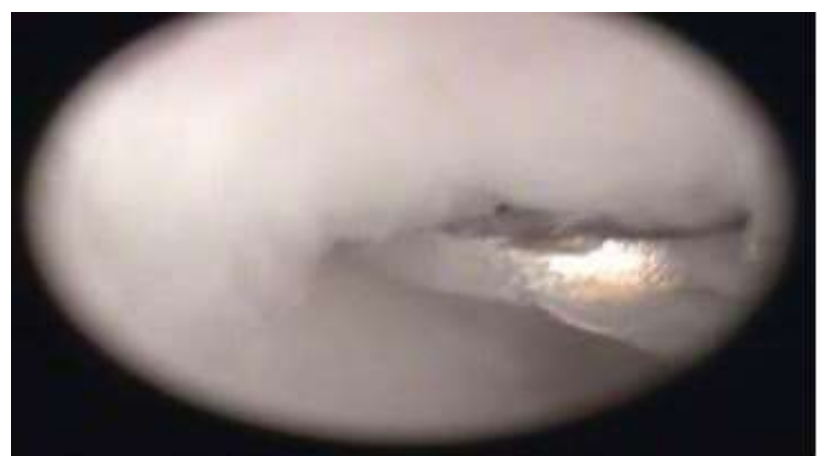

Figure 4: Arthroscopic picture of dorsal synovitis.

The portals were closed and compressive dressing was given. The patient was discharged the same day and encouraged to start wrist range of motion. The patients 
were followed up once every week for the first four weeks followed by once a month. The sutures were removed on the fifth post-operative day. The duration the patient took to return to a painless wrist with full range of motion was noted. Patient satisfaction with respect to cosmesis and function was noted.

\section{RESULTS}

The 21 patients included in this study comprised of 5 males and 16 females with a mean age of 23.3 years (range: 13 to 35 years). Right wrist was affected in 15 cases and left wrist was affected in 6 cases. Pre-operative wrist pain was present in 3 patients, cosmesis was a complaint in 6 patients and cosmesis and wrist pain was present in 12 patients. 5 patients had a pre-operative restricted range of motion. The mean duration of the ganglion was 2.6 months (range: 2 to 4 months).

The mean size of the ganglion at its largest dimension was $1.8 \mathrm{~cm}$ (range: 1 to $3 \mathrm{~cm}$ ). Arthroscopically, dorsal synovitis was present in 10 patients (Figure 4), triangular fibro-cartilage complex (TFCC) tear in 2 patients and chondral injury in 1 patient (Figure 5).

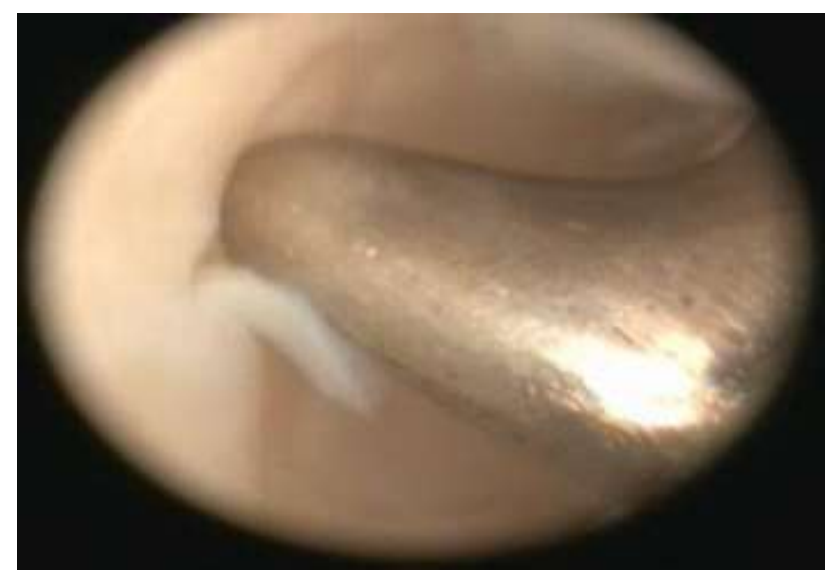

Figure 5: Arthroscopic picture of chondral lesion over the articular surface of radius.

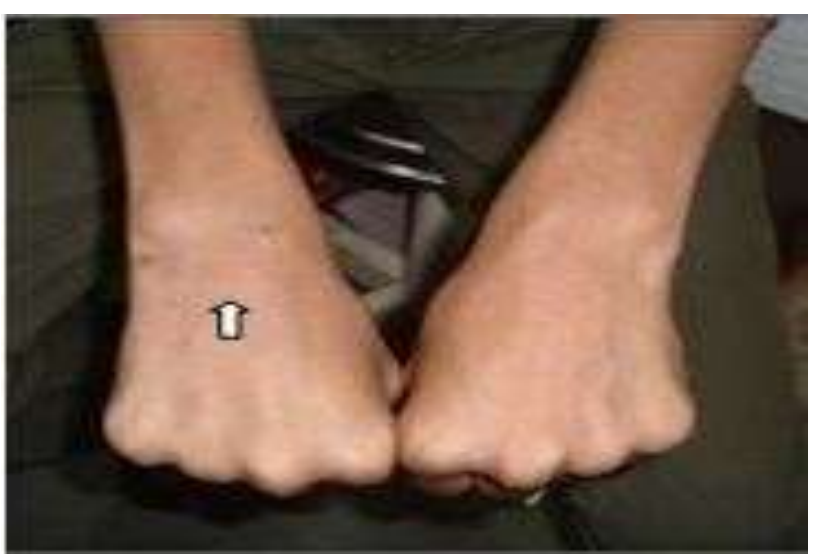

Figure 6: Cosmetic result at latest follow up (white arrow showing the operated hand).
The ganglion stalk was visualized in 14 patients. The mean duration of follow up was 14.6 months (range: 3 to 24 months). Complete painless range of motion of the wrist was obtained in 14 patients by 2 weeks and in 6 patients by 3 weeks.

One patient did not recover complete range of motion and had a 10 degree restriction in wrist palmar and dorsiflexion at the last follow-up. Recurrence was noted in the same patient. All the remaining patients were satisfied cosmetically and functionally with the results (Figure 6).

\section{DISCUSSION}

Dorsal wrist ganglion is the most common type of ganglion arising from the hand. The etio-pathogenesis of ganglia remains controversial although theories like mucoid degeneration of collagen tissue, repetitive microtrauma, occupational, intra-articular pathology and scapho-lunate instability have been described. ${ }^{2,4,5}$ Patients with dorsal wrist ganglia usually complain of dull aching pain which may be due to the ganglion location and its close relation to the posterior interosseous nerve.

Some patients complain of pain during wrist movement especially extension. Patients frequently present due to cosmetic concern. In this study of 21 patients, 15 had wrist pain and cosmetic concern (due to the "bump") was present in 18 patients. 5 patients had pre-operative restricted wrist range of motion. The symptoms improved to a painless wrist with complete range of movement in all patients except one by 2 to 3 weeks postoperatively.

The origin of dorsal ganglia is at the dorsum of the scapho-lunate interosseous ligament. The transition area between the interosseous ligament and dorsal capsule may serve as a tortuous duct that acts as a one way valve allowing fluid to enter the cyst from the joint. ${ }^{2}$ The success of any procedure would be directly related to its ability to identify and excise this one way valve mechanism. Spontaneous ganglia resolution has been reported between $28 \%$ and $58 \%$. $^{46}$ Success rate of nonoperative management like rupturing with a Bible, mallet or doctors thumb is approximately 50\%. ${ }^{7}$ Aspiration, with or without steroid, has a success rate of $35 \%$ to $50 \%{ }^{8,9}$

Open surgical excision of the ganglion cyst has lowered the recurrence rate to $10 \%$ to $40 \%$. $^{2,3}$ The key to open surgical excision is identification of the stalk and its removal from the base of the scapho-lunate interosseous ligament along with the surrounding capsule. In open surgical excision, the patient is trading a "bump" for a scar. This is especially true for young women presenting with only cosmetic concern due to the ganglion swelling. The scar of surgery may be associated with numbness distally and around the scar due to iatrogenic injury to the dorsal sensory nerve branches. Wrist stiffness is frequently associated following open surgical excision. This may be due to prolong immobilization, closure of 
the dorsal capsule, excessive handling of the extensor tendons and damage to the extensor retinaculum. Damage to the scapho-lunate interosseous ligament while excising the stalk may cause iatrogenic scapho-lunate instability. ${ }^{10}$

Arthroscopic resection of dorsal wrist ganglion has several advantages. Most importantly it gives direct access to the dorsal aspect of the scapho-lunate ligament which is the most common site of the pathology. Precise identification and excision of the stalk under magnification from within the joint by debriding an area of 5 to $10 \mathrm{~mm}^{2}$ of the dorsal capsule ensures complete removal of the one way valve like mechanism and hence a very low recurrence rate. Osterman and Raphael did not report any recurrence in 18 cases. $^{11}$

Pederzini et al and Fontes each had one recurrence in 14 and 32 cases respectively. ${ }^{12,13}$ Luchetti et al had 2 recurrences in 34 cases. ${ }^{14}$ In the present study we were able to visualize the ganglion stalk in 14 cases. In the remaining 7 cases in which we were not able to visualize the ganglion stalk, we used a needle pierced percutaneously through the centre of the ganglion and entering the joint dorsally as a method to identify the site of the stalk. In the present study only one patient had a recurrence.

Being a minimally invasive procedure, the arthroscopic method permits immediate wrist movement to be started and hence allows for a more rapid return of wrist range of motion and faster return to daily activities and profession. All but one of our patients had a painless wrist with full range of motion by 2 to 3 weeks after surgery. It does not involve dissection and hence less likely to cause any injury to the sensory nerves. None of the patients in present study experienced any numbness around the portal site. The arthroscopic method allows for protection of the scapho-lunate interosseous ligament as it is directly visualized under well magnified condition and bright illumination and hence reduces the chances of injury to this ligament.

The portal is $3 \mathrm{~mm}$ in size and hence has a very good cosmetic appeal. Patients frequently prefer to trade a "bump" (ganglion swelling) for a portal rather than for a surgical scar. Out of 21 patients included in this study, 18 patients had concerns of cosmesis because of the ganglion swelling. Following arthroscopic resection, all of them were satisfied with respect to the cosmetic results.

Arthroscopic ganglion resection allows simultaneous evaluation and management of other intra-articular pathologies. Upto $42 \%$ cases with dorsal wrist ganglia have been reported to have intra-articular pathologies. ${ }^{11}$ This is not possible by the open surgical procedure. In our study of 21 patients, intra-articular pathology was found in 13 patients which included dorsal synovitis $(n=10)$, TFCC tear $(n=2)$ and chondral injury $(n=1)$. All of these were managed arthroscopically during the same procedure.

The primary complication of arthroscopic ganglion resection is recurrence. The reported recurrence rate following arthroscopic resection ranges from zero to $7 \% .^{11-14}$ This rate is still lower than that reported following open surgical excision. The main reason of recurrence is inability to identify the ganglion stalk. In our study, one patient had a recurrence. In this patient the stalk could not be identified.

We use a needle pierced though the centre of the ganglion to identify the region of the stalk in cases where it is not identifiable. This patient also had a chondral lesion of the radius and dorsal synovitis which were debrided. This pathology may have been a cause of recurrence.

This was the only patient in the study who was not satisfied with the result of surgery and had a 10 degree restriction in palmar and dorsiflexion of the wrist at last follow up. Visualization of the extensor tendons arthroscopically is an excellent landmark to ensure full thickness excision of the dorsal capsule. ${ }^{15}$

We were able to visualize the extensor tendons in all the cases included in this study. The extensor tendons are at risk of damage during arthroscopic surgery. However, the small joint instruments are not wide enough to capture the tendons and the entire procedure is done under magnified vision with good illumination and hence this risk is greatly lowered. Arthroscopic resection of dorsal wrist ganglion is not indicated for recurrent ganglia, previously operated cases, multi loculated ganglia and ganglia arising from atypical locations. Open surgical excision is the treatment of choice for these cases.

\section{CONCLUSION}

Arthroscopic resection is an effective treatment modality for symptomatic dorsal wrist ganglia with good functional and cosmetic result. It has relatively lower recurrence rate, lesser post-operative morbidities, better cosmetic result and provides an opportunity to identify and manage intra-articular pathologies.

\section{Funding: No funding sources \\ Conflict of interest: None declared \\ Ethical approval: Not required}

\section{REFERENCES}

1. Athanasian EA. Bone and soft tissue tumors. In: Green DP, Hotchkiss R, Pederson C, Wolfe S, eds. Green's operative hand surgery. 5th ed. New York: Churchill Livingstone. 2005:2211-64.

2. Angelides AC, Wallace PF. The dorsal ganglion of the wrist: its pathogenesis, gross anatomy and surgical treatment. J Hand Surg. 1976;1:228-35. 
3. Clay NR, Clement DA. The treatment of dorsal wrist ganglia by radial excision. J Hand Surg. 1988;13B:187-91.

4. Carp L, Stout AP. A study of ganglion with special reference to treatment. Surg Gynecol Obstet. $1938 ; 47: 460-8$.

5. Watson HK, Rogers WD, Ashmead DF. Reevaluating the cause of the wrist ganglion. J Hand Surg. 1989;14A:812-7.

6. Nelson CL, Sawmiller S, Phalen GS. Ganglions of the wrist and hand. J Bone Joint Surg. 1972;5A:1459-64.

7. McEvedy BV. Simple ganglia: a review of modes of treatment and an explanation for the frequent failures of surgery. Lancet. 1965;266:135.

8. Richman JA, Gelberman RH, Engher WD, Salamon PB, Bean DJ. Ganglions of the wrist and digits: results of treatment by aspiration and cyst wall puncture. J Hand Surg. 1987;12A:1041-3.

9. Zubowicz VN, Ischii $\mathrm{CH}$. Management of ganglion cysts of the hand by simple aspiration. J Hand Surg. 1987;12A:618-20.

10. Crawford GP, Taleisnik J. Rotary subluxation of the scaphoid after excision of dorsal carpal ganglion and wrist manipulation: a case report. J Hand Surg. 1983;8A:921-5.

11. Osterman AL, Raphael J. Arthroscopic resection of dorsal ganglion of the wrist, Hand Clinics. 1995;11:7-12.

12. Pederzini L, Ghinelli, Soragni O. Arthroscopic treatment of dorsal arthrogenic cysts of the wrist. Journal of Sports Traumatology and Related Research. 1995;17:210-5.

13. Fontes D. Ganglia treated by arthroscopy. In: Saffer P, Amaido PC, Foucher G, eds. Current practice in hand surgery. London, Martin Dunitz. 1997:283-90.

14. Luchetti R, Badia A, Alfarano M, Orbay J, Indriago I, Mustapha B. Arthroscopic resection of dorsal wrist ganglia and treatment of recurrences. J Hand Surg. 2000; 25B:38-40.

15. Gallego S, Mathoulin C. Arthroscopic resection of dorsal wrist ganglia: 114 cases with minimum follow-up of 2 years. Arthroscopy. 2010;26:167582.

Cite this article as: Patel MR, Butala UK, Chauhan VD, Thakor NS. Arthroscopic resection of dorsal wrist ganglion. Int J Res Orthop 2016;2:127-31. 